\title{
THERMAL-INSULATION PROPERTIES OF MULTILAYER TEXTILE PACKAGES
}

\author{
Małgorzata Matusiak*, Sylwia Kowalczyk \\ University of Technology, Faculty of Material Technologies and Textile Design, Institute of Textile Architecture \\ 90-924 Lodz, 116 Zeromski str. \\ *E-mail: malgorzata.matusiak@p.lodz.pl
}

\begin{abstract}
:
Thermal-insulation properties of textile materials play a significant role in material engineering of protective clothing. Thermal-insulation properties are very important from the point of view of thermal comfort of the clothing user as well as the protective efficiency against low or high temperature. Thermal protective clothing usually is a multilayer construction. Its thermal insulation is a resultant of a number of layers and their order, as well as the thermalinsulation properties of a single textile material creating particular layers. The aim of the presented work was to investigate the relationships between the thermal-insulation properties of single materials and multilayer textile packages composed of these materials. Measurement of the thermal-insulation properties of single and multilayer textile materials has been performed with the Alambeta. The following properties have been investigated: thermal conductivity, resistance and absorptivity. Investigated textile packages were composed of two, three and four layers made of woven and knitted fabrics, as well as nonwovens. On the basis of the obtained results an analysis has been carried out in order to assess the dependency of the resultant values of the thermal-insulation properties of multilayer packages on the appropriate values of particular components.
\end{abstract}

\section{Keywords:}

Thermal insulation, protective clothing, thermal resistance, equivalent thermal conductivity, multilayer packages

\section{Introduction}

Thermal-insulation properties of textile materials play a significant role in material engineering of protective clothing. Thermal-insulation properties are very important from the point of view of thermal comfort of a clothing user as well as clothing protective efficiency against low or high temperature. Thermal protective clothing usually is a multilayer construction. Winter outdoor clothing is aimed at protecting a human being against harsh environmental conditions, especially against cold. It has a multilayer structure in order to ensure a thermal comfort in winter outdoor climatic conditions. Multilayer textile packages for winter outdoor clothing consist of at least three layers (Figure 1) of different functions:

- Outer layer protecting against wind and rainfall; this layer also creates a clothing shell on which other functional elements (pockets, fasteners, flies) of clothing are placed.

- Middle thermo-insulating layer made of thermal-insulation nonwoven or other thermal insulating materials, such as feathers, wadding and so on; it protects the human body from excessive heat loss,

- Inner layer-lining, the nearest to human body; it should enable moisture and air exchange between the human body and surroundings.

Protective clothing against high temperature, for instance, firefighters clothing (Figure 2) has also multilayer structure. Each layer is created by single textile material of properties adequate to its function.

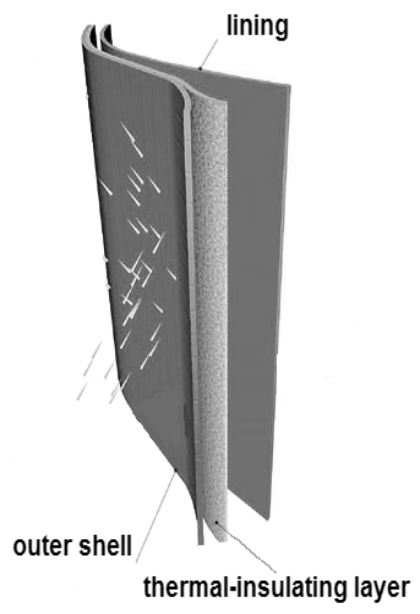

Figure 1. An example of protective clothing protecting against cold.

Thermal-insulation of multilayer textile packages is a resultant of the number of layers and the order, as well as the thermalinsulation properties, of the single textile material creating the particular layers. Thermal resistance, water-vapour resistance and air permeability are considered as crucial comfort-related properties of fabrics [1-6].

From the point of view of heat exchange between the human body and surroundings through clothing being a thermal barrier, particular layers create a series system. In such a 
system a total thermal resistance is approximately a sum of the thermal resistance of individual layers [1, 2, 7]. However, when two materials are joined together, their surfaces do not adjoin exactly to one another. Surface of solid objects is usually rough and due to this fact small air gaps occur between the objects (Figure 3). This air gaps create additional source of thermal resistance due to high thermal insulation of air trapped in the gaps between materials. The limited number and size of the contact spots between the adhering surfaces result, in fact, in that the actual contact area is significantly smaller than the apparent contact area. This limited contact area and air gaps between layers cause a thermal resistance called a contact resistance or thermal contact resistance [8].

The thermal contact resistance increases the total thermal resistance of the multilayer assembly. Therefore, the total thermal resistance of the multilayer textile package should be a little higher than the sum of thermal resistance of particular layers, according to the following equation

$$
R_{T}=R_{L 1}+R_{L 2}+\ldots+R_{L n}+R_{c}
$$

where $R_{T}$ - total thermal resistance of multilayer assembly, $R_{L 1}$ - thermal resistance of $1^{\text {st }}$ layer, $n$ - number of layers, $R_{c}-$ thermal contact resistance.

Thermal conductivity is a characteristic feature of material. In the case of multilayer textile packages each layer has its own thermal conductivity. However, in order to describe the multilayer assembly an effective or equivalent thermal conductivity can be applied. The equivalent (effective) thermal conductivity of multilayer package can be defined as a thermal conductivity of the homogenous material of the same thickness and ensuring in identical thermal conditions, that is, the same heat flow as the multilayer assembly. Investigations $[9,10]$ showed that the effective thermal conductivity of two-layer textile assembly is approximately equal to the weighted mean from the thermal conductivity of particular components with weights reflecting thickness of particular layers according to the equation

$$
\lambda_{\Phi}=\lambda_{I} \cdot \frac{h_{I}}{h_{I}+h_{O}}+\lambda_{O} \cdot \frac{h_{O}}{h_{I}+h_{O}}
$$

where $\lambda_{\text {ef }}$ - effective thermal conductivity of two-layer material, $\lambda_{l}$ - thermal conductivity of inner layer, $\lambda_{o}$ - thermal conductivity of outer layer, $h_{1}$ - thickness of inner layer, $h_{0}-$ thickness of outer layer.

Particular thermal properties of individual textile materials can be measured using different devices: sweating guarded hotplate called 'skin model', Alambeta, Permetest and Thermo Labo [2, 11 - 14]. However, in order to predict the thermal-insulation properties of the multilayer textile packages it is necessary to know the relationships between the thermal properties of individual textile materials and thermal properties of multilayer textile assemblies made of those individual materials. Thermalinsulation properties of multilayer textile assemblies have been the objects of investigations [1, 2, 11]. Nevertheless, the topic is still open and worth investigating.

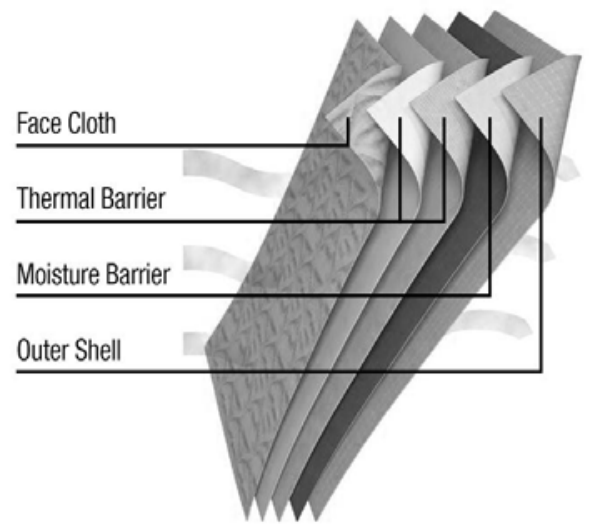

Figure 2. An example of protective clothing - Firefighter LION's Janesville $\circledR$ V-Force $®$ garment [http://www.prweb.com].

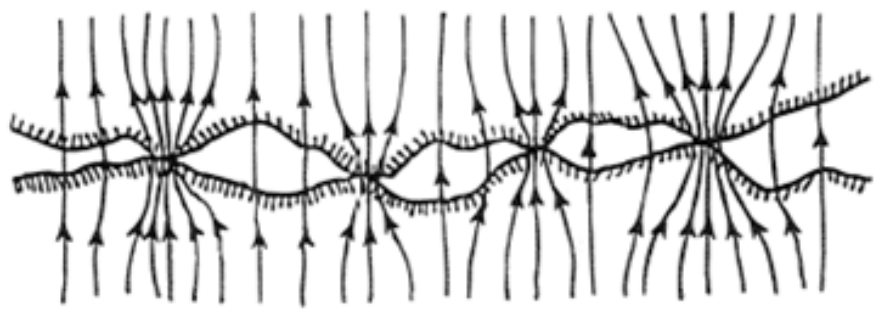

Figure 3. Heat flow through the air gaps between layers [http://www. thermopedia.com/content/1188/].

\section{Experimental}

The aim of presented work was to investigate the relationships between the thermal-insulation properties of single textile materials and multilayer packages composed of these materials [15].

\subsection{Materials}

Different textile materials have been applied to create the multilayer textile packages. They were:

- Two variants of woven fabrics: T1 and T2.

- Two variants of knitted fabrics: D1 and D2.

- Two variants of nonwovens W1 and W2.

Above textile materials have been applied in multilayer assemblies. Placement of individual materials in multilayer assemblies was in agreement with their functions resulted from fabric structure and properties. The woven fabric T1 created an outer shell of clothing; whereas, the woven fabric T2 created the lining. Nonwovens W1 and W2, as well as polar D2, have been applied as inner thermal-insulating layers. Additionally, in fourlayer assemblies the knitted fabric D1 simulated underwear. A set of variants of created multilayer textile packages is presented in Table 1. 
Table 1. A set of variants of created multilayer textile packages.

\begin{tabular}{|c|c|c|}
\hline \multicolumn{3}{|c|}{ Multilayer packages } \\
\hline 2-layer & 3-layer & 4-layer \\
\hline $\mathrm{T} 1+\mathrm{W} 1$ & $\mathrm{~T} 1+\mathrm{W} 1+\mathrm{T} 2$ & $\mathrm{~T} 1+\mathrm{W} 1+\mathrm{T} 2+\mathrm{D} 1$ \\
\hline $\mathrm{T} 1+\mathrm{D} 2$ & $\mathrm{~T} 1+\mathrm{D} 2+\mathrm{T} 2$ & $\mathrm{~T} 1+\mathrm{D} 2+\mathrm{T} 2+\mathrm{D} 1$ \\
\hline $\mathrm{T} 1+\mathrm{W} 2$ & $\mathrm{~T} 1+\mathrm{W} 2+\mathrm{T} 2$ & $\mathrm{~T} 1+\mathrm{W} 2+\mathrm{T} 2+\mathrm{D} 1$ \\
\hline
\end{tabular}

Single textile materials used to create the multilayer packages have been measured in the range of their basic structural and mechanical parameters according to the standardized procedures. The basic characteristics of the materials creating particular layers in experimental packages are presented in Tables 2-4.

Table 2. Basic parameters of investigated woven fabrics.

\begin{tabular}{|c|c|c|c|}
\hline \multirow{2}{*}{ Parameter } & \multirow{2}{*}{ Unit } & \multicolumn{2}{|c|}{ Value } \\
\cline { 3 - 4 } & & T1 & T2 \\
\hline Raw material of warp & - & CO & CO \\
\hline Raw material of weft & - & $\begin{array}{c}\text { CO 50 PES } \\
50\end{array}$ & CO \\
\hline Warp linear density & tex & 60 & 30 \\
\hline Weft linear density & tex & 50 & 50 \\
\hline Weave & - & plein & Twill 3/1 S \\
\hline Warp density & $\mathrm{dm}^{-1}$ & 320 & 248 \\
\hline Weft density & $\mathrm{dm}^{-1}$ & 118 & 112 \\
\hline $\begin{array}{c}\text { Mass per square } \\
\text { meter }\end{array}$ & $\mathrm{gm}^{-2}$ & 270 & 134 \\
\hline Thickness & $\mathrm{mm}^{\text {Wmy }}$ & 0.63 & 0.54 \\
\hline
\end{tabular}

Table 3. Basic parameters of investigated knitted fabrics.

\begin{tabular}{|c|c|c|c|}
\hline \multirow{2}{*}{ Parameter } & \multirow{2}{*}{ Unit } & \multicolumn{2}{|c|}{ Value } \\
\cline { 3 - 4 } & & D1 & D2 (polar) \\
\hline Raw material & - & CO & PES \\
\hline Weave & - & Interlock & polar \\
\hline Cours density & $\mathrm{cm}^{-1}$ & 7.6 & - \\
\hline Wale density & $\mathrm{cm}^{-1}$ & 13.2 & - \\
\hline $\begin{array}{c}\text { Mass per square } \\
\text { meter }\end{array}$ & $\mathrm{gm}^{-2}$ & 201 & 259 \\
\hline Thickness & $\mathrm{mm}$ & 1.17 & 2.84 \\
\hline
\end{tabular}

Table 4. Basic parameters of investigated nonwovens.

\begin{tabular}{|c|c|c|c|}
\hline \multirow{2}{*}{ Parameter } & \multirow{2}{*}{ Unit } & \multicolumn{2}{|c|}{ Value } \\
\cline { 3 - 4 } & W 1 & W 2 \\
\hline $\begin{array}{c}\text { Mass per square } \\
\text { meter }\end{array}$ & $\mathrm{gm}^{-2}$ & 78,4 & 62,3 \\
\hline Thickness & $\mathrm{mm}$ & 3,77 & 1,18 \\
\hline
\end{tabular}

\subsection{Methods}

Both single and multilayer materials have been measured in the range of they thermal properties by means of the Alambeta. It is a computer-controlled instrument for measuring the basic static and dynamic thermal characteristics of textiles [2-4, 11]. The Alambeta is a plate method whose operating principle depends on the convection of heat emitted by a hot upper plate in one direction through the examined sample to the cold bottom plate adjoined to the sample.

The instrument directly measures:

- The stationary heat flow density (by measuring the electric power at the known area of the plates).

- The temperature difference between the upper and lower fabric surface.

- The fabric thickness.

The device calculates the real thermal resistance for all fabric configurations. Thermal conductivity and thermal absorptivity, as well as the thermal diffusivity, are calculated on the basis of the measured properties using algorithms appropriate for the homogenous materials. Due to this fact in the case of the multilayer textile packages the results calculated on the basis of the measured parameters should be considered as equivalent values, i.e. equivalent conductivity, equivalent absorptivity and equivalent diffusivity.

While measuring the multilayer assemblies they were placed in such a way that configuration of layers reflected the place of layer in clothing during usage with respect of left and right side of the particular materials. It means that the inner layer adjoined the upper hot plate of the device simulating a human body; whereas, the outer woven fabric adjoined the bottom cold plate. An example of the layers' configuration during measurement is presented in Figure 4.

Measurements by means of the Alambeta have been performed in standard conditions. For each sample: single and multilayer, 10 repetitions have been done. Next an arithmetic mean has been calculated as a final result for the given sample.

By means of the Alambeta the following properties have been assessed:

- Thermal conductivity.

- Thermal diffusivity.

- Thermal absorptivity.

- Thermal resistance.

- Sample thickness.

- Peak heat flow density.

- Ratio of peak heat flow density and stationary heat flow density.

In the article the thermal conductivity and resistance are discussed. 


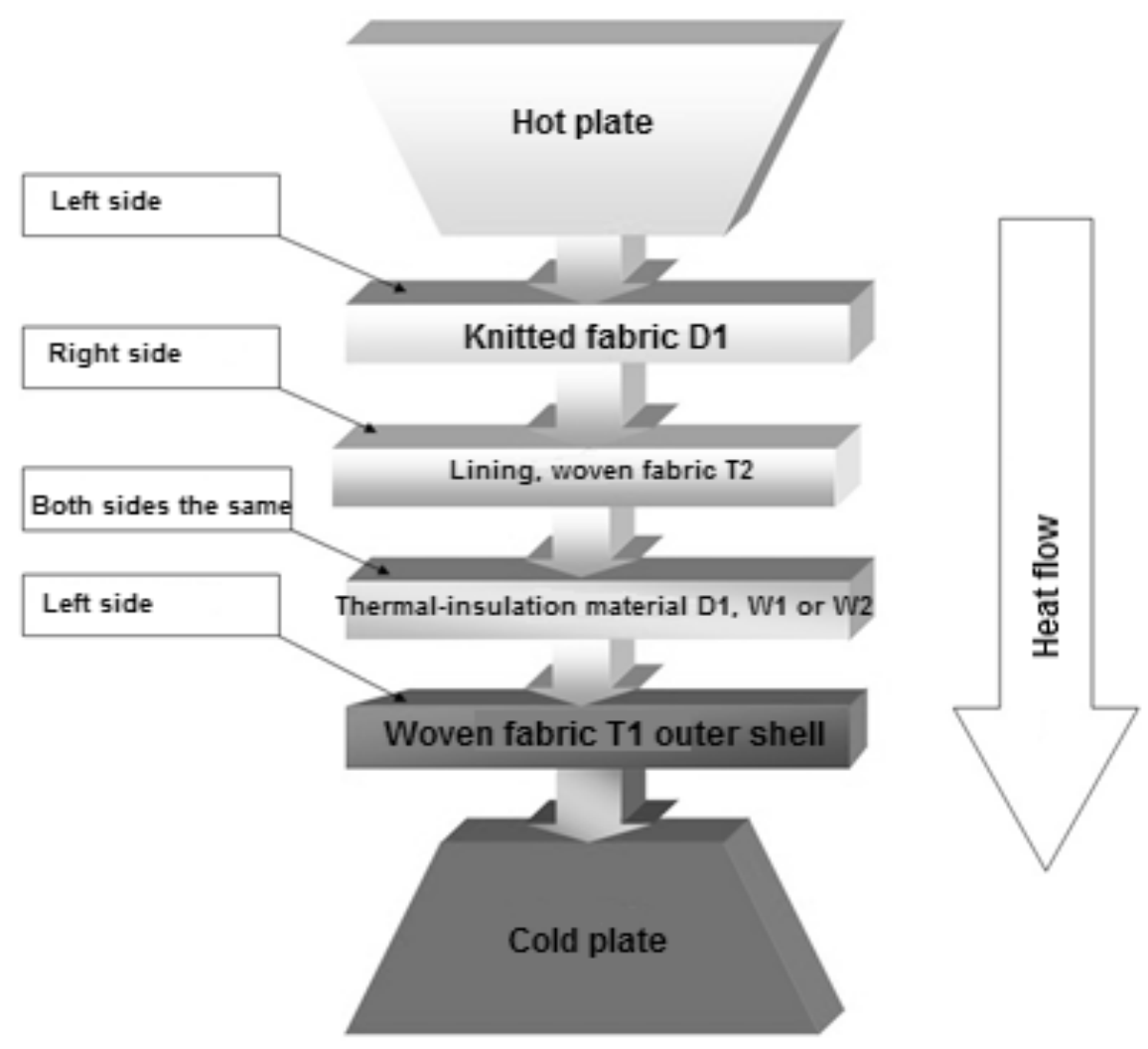

Figure 4. Configuration of layers during measurement by means of Alambeta.

\section{Results and discussion}

Results of the measurement of individual materials are presented in Table 5.

Table 5. Results of measurement of individual fabrics by means of Alambeta

\begin{tabular}{|c|c|c|c|c|}
\hline \multirow{2}{*}{ Sample } & \multicolumn{2}{|c|}{$\begin{array}{c}\text { Thermal } \\
\text { conductivity } \\
\mathbf{W m}^{-1} \mathbf{K}^{-1} \mathbf{x} \mathbf{1 0}^{-3}\end{array}$} & \multicolumn{2}{c|}{$\begin{array}{c}\text { Thermal resistance } \\
\mathbf{~}^{2} \mathbf{K W}^{-1} \mathbf{x} \mathbf{1 0}^{-3}\end{array}$} \\
\cline { 2 - 5 } & $\overline{\mathbf{a}}$ & $\mathbf{S D}$ & $\overline{\mathbf{a}}$ & SD \\
\hline $\mathrm{T} 1$ & 69.45 & 2.86 & 8.99 & 0.37 \\
\hline $\mathrm{T} 2$ & 48.78 & 0.54 & 11.49 & 0.42 \\
\hline $\mathrm{D} 1$ & 55.17 & 1.62 & 23.41 & 0.74 \\
\hline $\mathrm{D} 2$ & 44.29 & 0.88 & 74.31 & 1.71 \\
\hline $\mathrm{W} 1$ & 39.10 & 1.17 & 76.73 & 6.41 \\
\hline W2 & 33.56 & 1.15 & 45.12 & 1.32 \\
\hline
\end{tabular}

According to expectation the highest thermal resistance was stated for nonwovens samples: W1 and W2, as well as for polar D2. Mentioned fabrics have been applied in investigated multilayer textile packages as thermo-insulation layers. The lowest thermal resistance occurred for woven fabrics T1 and T2. They have been introduced appropriately as an outer shell and lining of created packages.

Results for multilayer packages are presented in Table 6.

Table 6. Results of the measurement of multilayer packages by means of the Alambeta.

\begin{tabular}{|c|c|c|c|c|}
\hline \multirow{2}{*}{$\begin{array}{c}\text { Sample } \\
\text { configuration }\end{array}$} & \multicolumn{2}{|c|}{$\begin{array}{c}\text { Thermal } \\
\text { conductivity } \\
\mathbf{W m}^{-1} \mathbf{K}^{-1} \mathbf{x} \mathbf{1 0}^{-3}\end{array}$} & \multicolumn{2}{|c|}{$\begin{array}{c}\text { Thermal } \\
\text { resistance } \\
\mathbf{m}^{2} \mathbf{K W}^{-1} \mathbf{x} \mathbf{1 0}^{-3}\end{array}$} \\
\cline { 2 - 5 } & $\overline{\mathbf{a}}$ & SD & $\overline{\mathbf{a}}$ & SD \\
\hline $\mathrm{T} 1+\mathrm{W} 1$ & 45.03 & 0.78 & 76.68 & 5.01 \\
\hline $\mathrm{T} 1+\mathrm{D} 2$ & 50.47 & 1.04 & 79.18 & 1.72 \\
\hline $\mathrm{T} 1+\mathrm{W} 2$ & 42.30 & 0.50 & 52.66 & 2.36 \\
\hline $\mathrm{T} 1+\mathrm{W} 1+\mathrm{T} 2$ & 57.81 & 2.54 & 71.55 & 4.58 \\
\hline $\mathrm{T} 1+\mathrm{D} 2+\mathrm{T} 2$ & 59.25 & 1.84 & 76.91 & 3.03 \\
\hline $\mathrm{T} 1+\mathrm{W} 2+\mathrm{T} 2$ & 51.51 & 1.29 & 54.56 & 2.52 \\
\hline $\mathrm{T} 1+\mathrm{W} 1+\mathrm{T} 2+\mathrm{D} 1$ & 69.65 & 3.07 & 77.92 & 4.43 \\
\hline $\mathrm{T} 1+\mathrm{D} 2+\mathrm{T} 2+\mathrm{D} 1$ & 71.26 & 4.12 & 82.84 & 4.53 \\
\hline $\mathrm{T} 1+\mathrm{W} 2+\mathrm{T} 2+\mathrm{D} 1$ & 62.38 & 1.09 & 66.26 & 2.12 \\
\hline
\end{tabular}


Comparison of thermal resistance of multilayer packages and individual materials creating the package is presented in Figures 5-7.
In the case of the two-layer packages it can be seen that the total thermal resistance of the packages is a little higher than thermal resistance of inner thermal-insulation layer (layer L2). For the

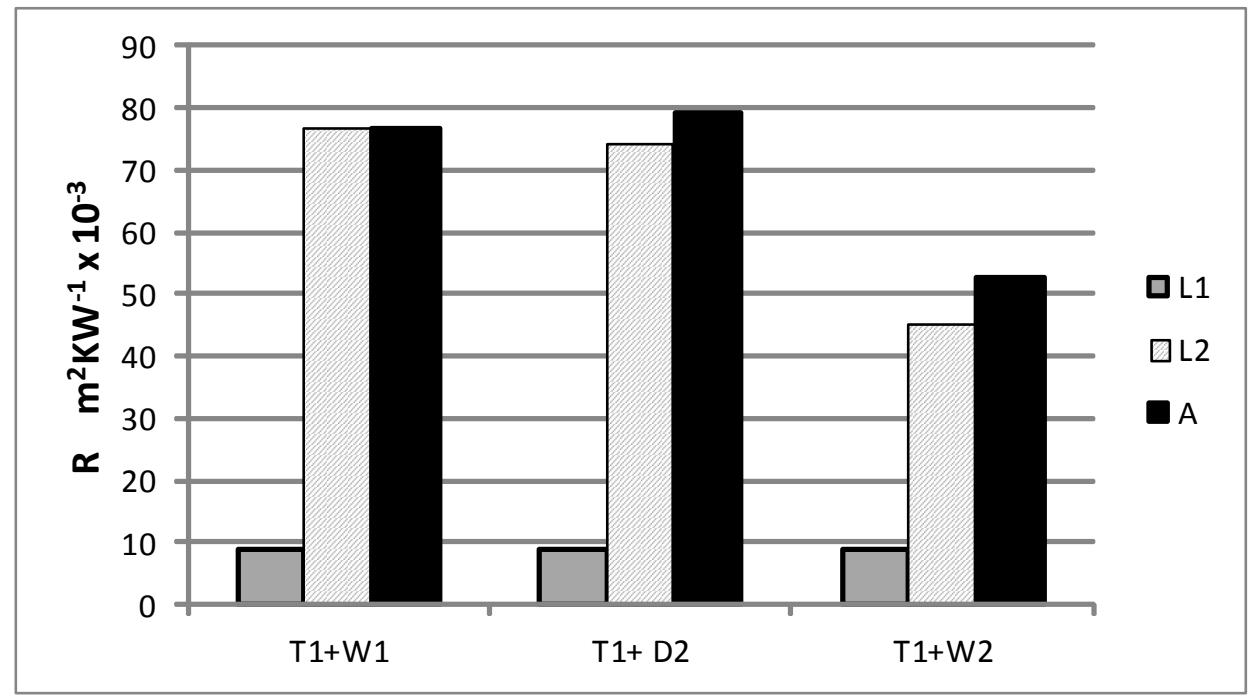

Figure 5. Thermal resistance of two-layer assemblies: L1 - outer layer, L2 - inner layer, A - assembly.

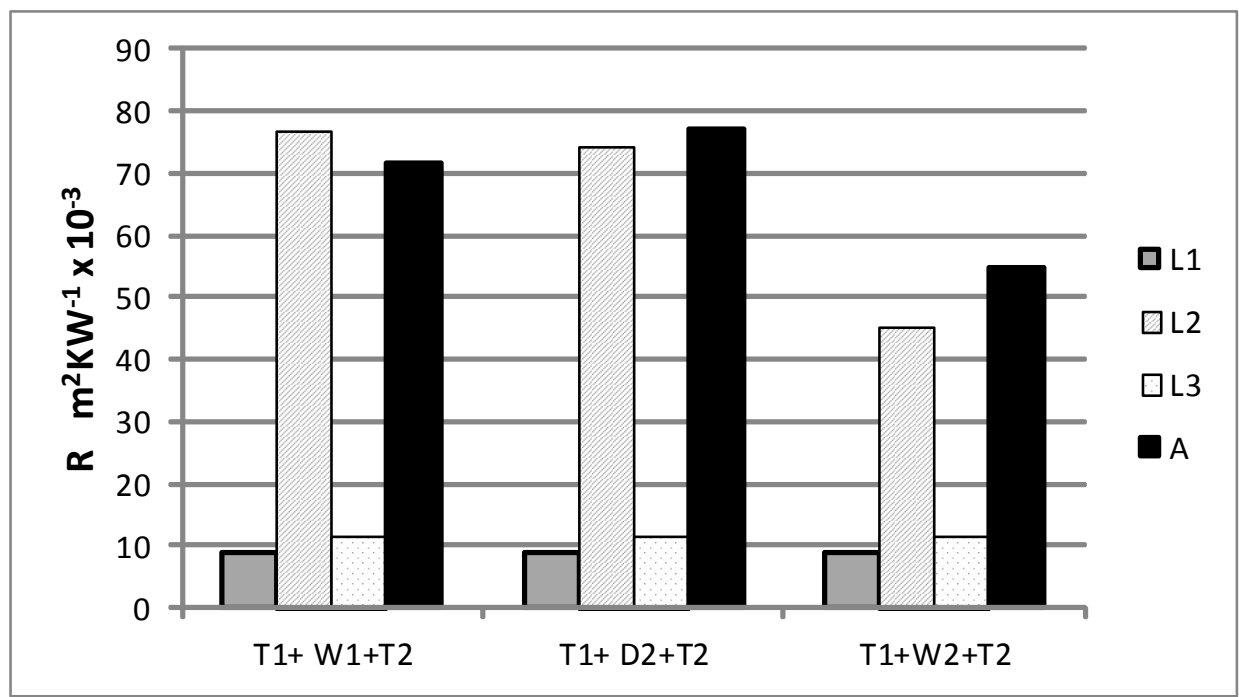

Figure 6. Thermal resistance of three-layer assemblies: L1 - outer layer, L2 - inner layer, L3 - lining, A - assembly.

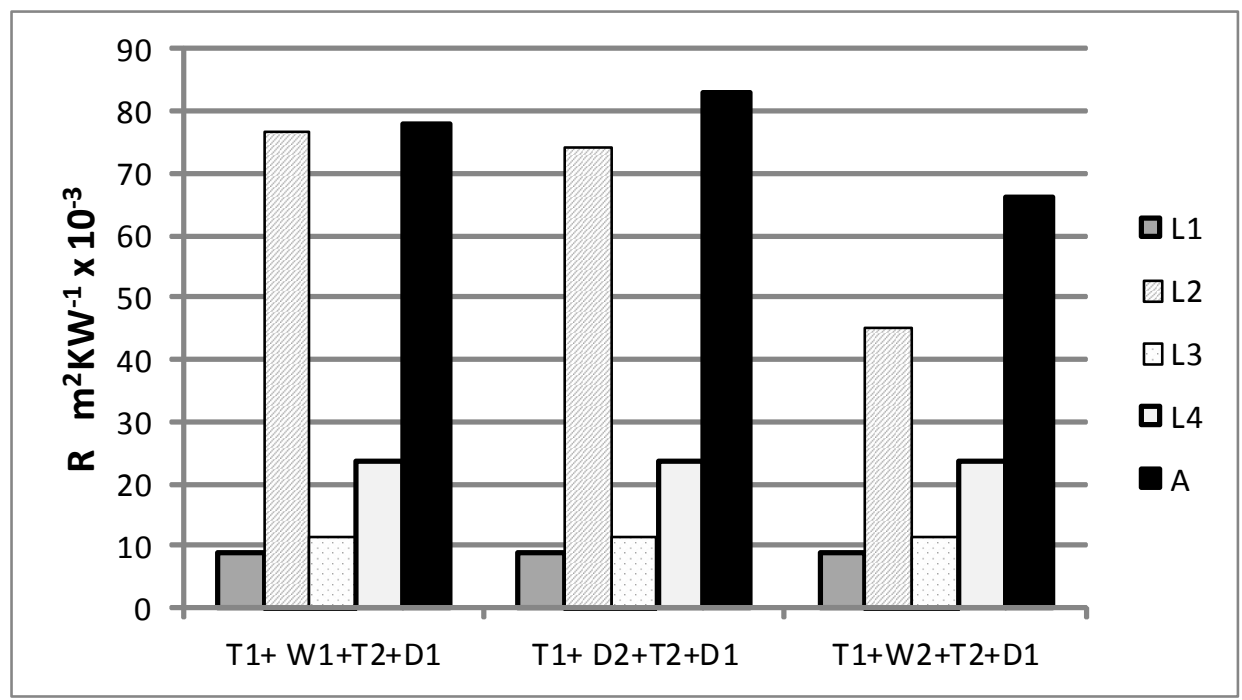

Figure 7. Thermal resistance of four-layer assemblies: L1 - outer layer, L2 - inner layer, L3 - lining, L4 - knitted underwear, A - assembly. 
three- and four-layer packages the total thermal resistance is also close to the thermal resistance of the component crating the thermo-insulation layer. Thermal resistance of the multilayer packages has been also compared with a sum of thermal resistance of particular layers. A comparison is shown in Figure 8.

In all cases the real (measured) thermal resistance of the multilayer packages is lower than the calculated sum of the thermal resistance of individual layers. It means that the thermal contact resistance did not occur.

How can be this phenomenon explained? Due to the flexibility and structure of textile materials, especially their texture, different directions of fibres in particular materials creating layers, two factors can occur:

- Increased number of contact points.

- Fulfilling the pores in one layer by the elements of adjacent layer.
As a consequence, in comparison to the assemblies made of solid, rigid materials the textile multilayer assemblies have more tight structure (Figure 9) with lower amount of air inside that results in lower thermal resistance.

Moreover, it was stated that bigger the number of layers higher the difference between the measured thermal resistance of the multilayer package and calculated sum of thermal resistance of individual materials creating the package.

Equivalent thermal conductivity of multilayer packages differs significantly between each other (Figures 10-12). It is also observed that the equivalent thermal conductivity of multilayer assemblies is different that the thermal conductivity of particular layers. In the case of two-layer assemblies their equivalent thermal conductivity is in the range between the thermal conductivity of the outer layer and thermal conductivity of the inner layer (Figure 10). Similarly, the thermal conductivity of three-layer assemblies is in the range limited by the thermal conductivity of layers of the highest and the lowest value of this parameter.

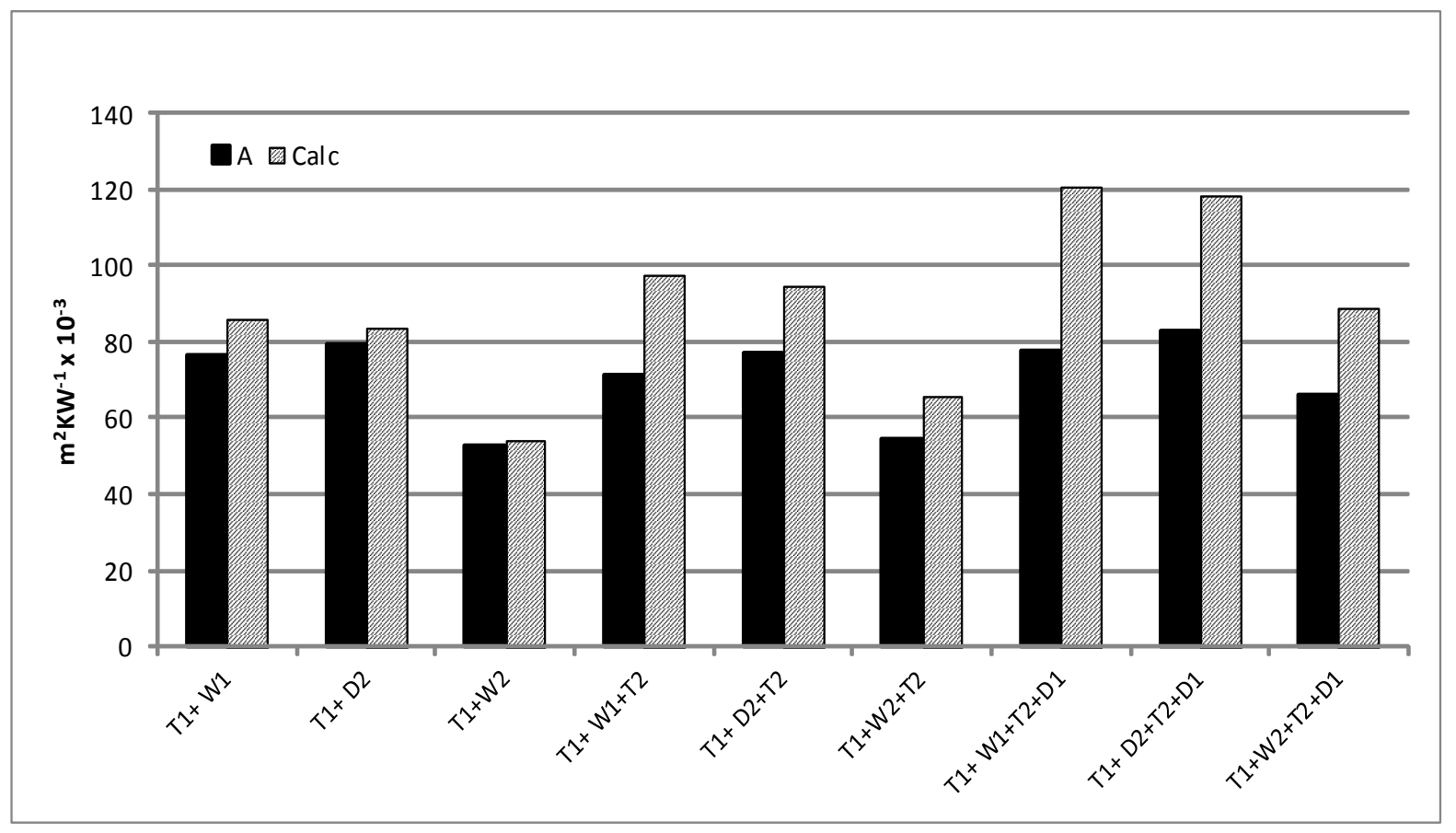

Figure 8. Comparison of thermal resistance of multilayer assemblies: measured by means of the Alambeta (A) and calculated as a sum of the thermal resistance of particular layers (Calc).

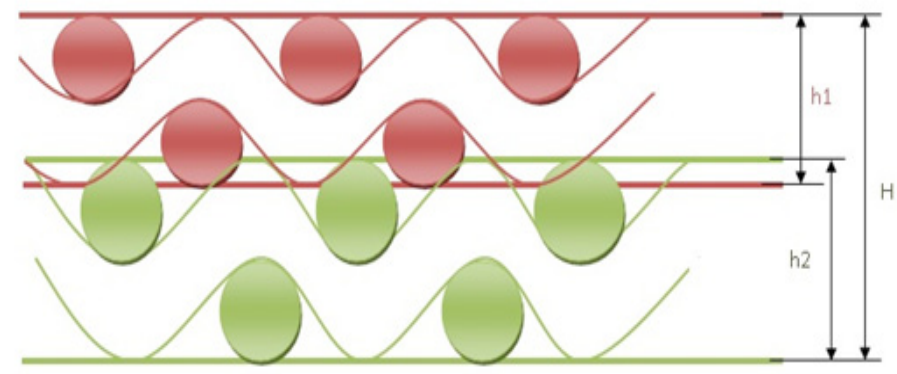

Figure 9. Schematic cross-section of multilayer textile assembly. 
Surprising results have been stated in the case of fourlayer packages (Figure 12). For two variants the equivalent thermal conductivity of the assembly is slightly higher than the thermal conductivity of individual layer of the highest value of thermal conductivity. It is difficult to explain this phenomenon.

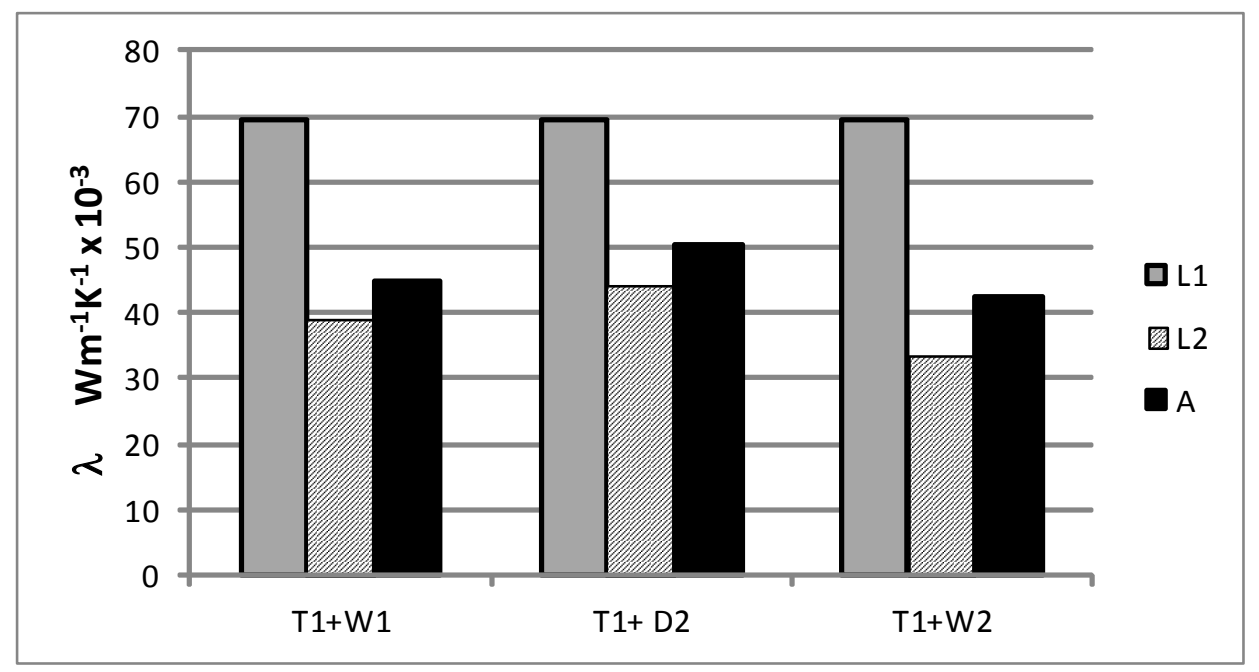

Figure 10. Thermal conductivity of two-layer assemblies: L1 - outer layer, L2 - inner layer, A - assembly.

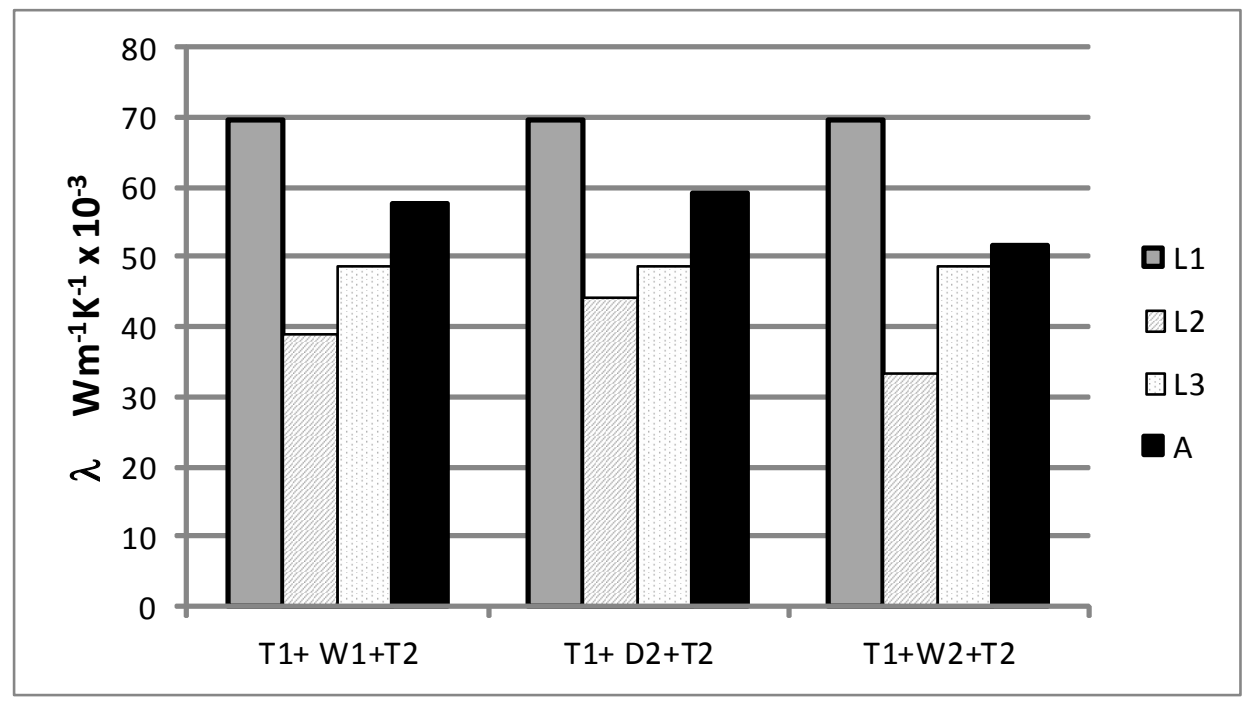

Figure 11. Thermal conductivity of three-layer assemblies: L1 - outer layer, L2 - inner layer, L3 - lining, A - assembly.

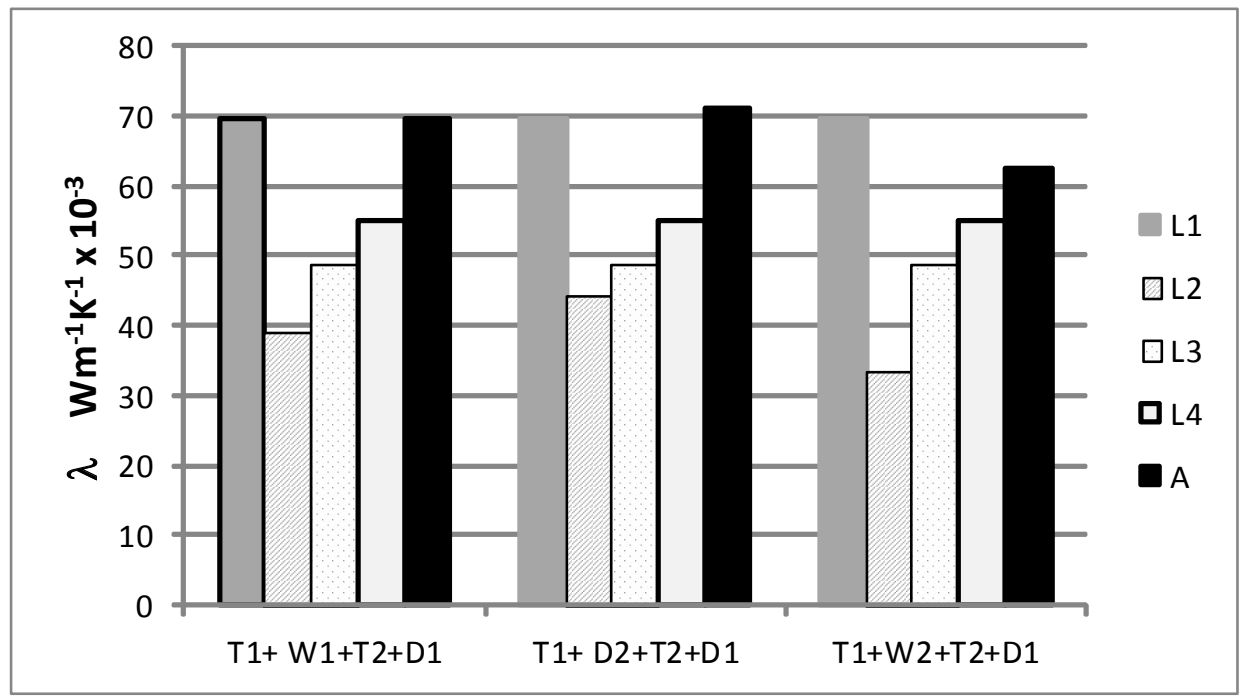

Figure 12. Thermal conductivity of four-layer assemblies: L1 - outer layer, L2 - inner layer, L3 - lining, L4 - knitted underwear A - assembly. http://www.autexrj.com/ 
In order to analyse the relationships between the equivalent thermal conductivity of multilayer assembly and thermal conductivity of particular layers, the values of thermal conductivity of multilayer assemblies measured by the Alambeta have been compared with the values of weighted mean calculated on the basis of the results for individual materials according to the equation

$\lambda_{e}=\lambda_{1} \cdot \frac{h_{1}}{h_{1}+h_{2}+\cdots+h_{n}}+\lambda_{2} \cdot \frac{h_{2}}{h_{1}+h_{2}+\cdots+h_{n}}+\cdots+\lambda_{n} \cdot \frac{h_{n}}{h_{1}+h_{2}+\cdots h_{n}}$

where $\lambda_{e}$ - equivalent thermal conductivity of multilayer textile package, $\lambda_{i}$ - thermal conductivity of $i$-tch layer, $h_{i}$ - thickness of $i$-tch layer, $n-$ number of layers.

The results of the comparison are presented in Figure 13.

According to the results presented in Figure 13 it can be seen that in the case of two-layer assemblies the equivalent thermal conductivity of the assembly measured by means of the Alambeta is close to weighted mean from the thermal conductivity of individual materials with weights equivalent to thickness of individual materials. In the same time the results for two-layer packages confirmed Equation (2). However, in the case of three- and four-layer textile packages, the situation is different. There is significant difference between the measured equivalent thermal conductivity of the package and calculated mean value. Similarly to the thermal resistance the difference between the measured equivalent thermal conductivity of the assembly and weighted mean value with weight equivalent to thickness of particular layers is higher for four-layer assemblies than for three-layer assemblies. It suggests that each next apply of adjoining layer to the existing set of materials causes an increase of difference between the equivalent thermal conductivity of assembly measured by the Alambeta and weighted mean value of thermal conductivity calculated according to Equation (3).

\section{CONCLUSIONS}

On the basis of carried out investigation the following conclusions can be drawn:

- Thermal resistance of two-layer textile package is close to the sum of thermal resistance of particular materials creating layers.

- Thermal resistance of investigated multilayers assemblies is lower than the sum of thermal resistance of particular components.

- Difference between the measured thermal resistance of the investigated multilayer textile packages and a sum of thermal resistance of components increases with an increase of number of layers.

- Investigations confirmed that the equivalent thermal conductivity of two-layer textile assembly is approximately equal to the weighted mean of thermal conductivity of particular components with weights reflecting a thickness of layers.

- In the case of assemblies composed of more than two layers the equivalent thermal conductivity significantly differs from the weighted mean from thermal conductivity of the components.

- On the basis of the measurement of single textile materials it is possible to predict the thermal resistance and equivalent thermal conductivity of two-layer packages.

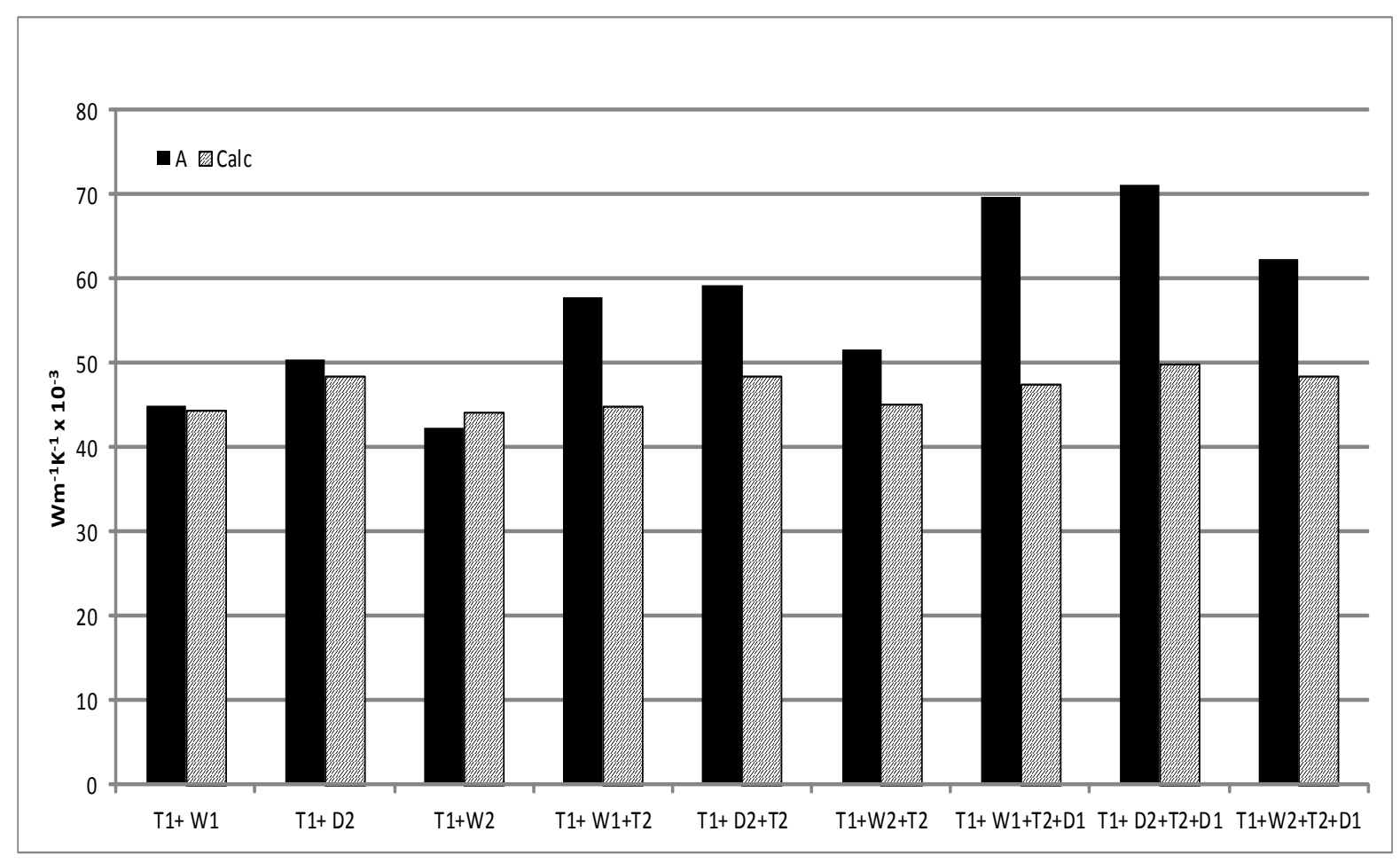

Figure 13. Comparison of the equivalent thermal conductivity of multilayer assemblies measured by means of the Alambeta (A) and calculated as a weighted mean from the thermal conductivity of particular layers (Calc). 
- Prediction of thermal-insulation properties of textile packages composed of more than two layers needs further investigations.

\section{References}

[1] Das A., Alagirusamy R., Kumar P., Study of Heat Transfer through Multilayer Clothing Assemblies: A Theoretical Prediction, AUTEX Research Journal, Vol. 11, No2, June 2011.

[2] Matusiak M., Thermal Insulation Properties of Single and Multilayer Textiles, Fibres \& Textiles in Eastern Europe No 14, 5(59) (2006), pp. 98-112.

[3] Hes L., Marketing Aspects of Clothing Comfort Evaluation, Book of Proceedings of the $X$. International Textile and Apparel Symposium, Izmir (2004).

[4] Matusiak M., Sikorski K., Influence of Structure of Woven Fabrics on their Thermal Insulation Properties, Fibres \& Textiles in Eastern Europe 2011, Vol. 19, No. 5 (88).

[5] Hes, L., Araujo, M., Djulay, V., Effect of Mutual Bonding of Textile Layers on Thermal Insulation and Thermal Contact Properties of Fabric Assemblies, Textile Research Journal 66 (1996), p. 245.

[6] Matusiak M., Thermal Comfort Index as a Method of Assessing the Thermal Comfort of Textile Materials, Fibres \& Textiles in Eastern Europe, Volume 79, Issue 2 (2010), pp. 45-50,

[7] Pogorzelski J. A., Fizyka budowli część V, Przenikanie ciepła w stanie ustalonym przez przegrody budowlane wg PN-EN, (in Polish) Podręcznik fizyki budowli, Instytut
Techniki Budowlanej (2004).

[8] Thermal contact resistance, Thermopedia, DOI 10.1615, [available 22.07.2014 in: http://www.thermopedia.com/ content/1188/]

[9] Matusiak M., Thermal-insulation of the woven fabrics for clothing Monograph (in Polish), Textile Research Institute, Lodz, 2011, ISBN 978-83-911544-7-2.

[10] Matusiak M., Investigation of the Effective Thermal Conductivity of Multilayer Textile Materials, Proceedings of $12^{\text {th }}$ World Textile Conference AUTEX'2012, June 2012, Zadar, Croatia.

[11] Hes L., Araujo M., Djulay V., Effect of Mutual Bonding of Textile Layers on Thermal Insulation and Thermal Contact Properties of Fabric Assemblies, Textile Research Journal 66, (1996), p. 245.

[12] Hes L., Alternative Methods of Determination of Water Vapour Resistance of Fabrics by Means of a Skin Model, 3rd European Conference on Protective Clothing and NOKOBETEF 8, Gdynia (2006).

[13] Hes L., Dolezal I., A New Computer-Controlled Skin Model for Fast Determination of Water Vapour and Thermal Resistance of Fabrics, $7^{\text {th }}$ Asian Textile Conference, New Delhi 2003.

[14] Yoneda M., Kawabata S., Analysis of Transient Heat Conduction in Textiles and its Applications, Part II, Journal of Textile Machinery Society of Japan 31, 1983, 73-81.

[15] Kowalczyk S., Investigation of Thermal-insulation Parameters of Multilayer Clothing Packages, Degree thesis, Department of Material Technologies and Textile Design, Lodz University of Technology, 2014. 